\title{
Trabalho doméstico de adolescentes e reprodução das desiguais relações de gênero
}

\author{
Munich Santana* \\ Magda Dimenstein ${ }^{* *}$
}

\begin{abstract}
Resumo
Pretendemos discutir o trabalho doméstico de adolescentes na perspectiva das relações de gênero, articulando-o com as categorias de classe social, etnia e intergeracionalidade. Utilizamos os resultados de uma pesquisa realizada em Natal (RN), a qual destaca que as jovens começam a trabalhar muito cedo, acumulando tarefas escolares e de trabalho e sob condições trabalhistas desiguais, com baixos salários, muitas horas e a presença de trabalho noturno, o que é proibido para menores de 18 anos. Trata-se de uma forma de trabalho desvalorizada, rotineira e desestimulante. Além disso, reproduz muitos conflitos sociais, principalmente aqueles relacionados a gênero, já que é uma forma de perpetuar o espaço doméstico como destinado à figura feminina, reproduzindo a divisão sexual do trabalho. Apesar disso, tem um sentido positivo na vida das jovens, pois é uma forma de ascensão social, de ter mais autonomia, bem como ajudar suas famílias que se encontram, geralmente, no interior do estado.

Palavras-Chave: Trabalho doméstico; Adolescente; Mulheres; Relações de gênero; Esfera privada.
\end{abstract}

\section{Domestic labour of adolescents and reproduction of unequal gender relationships}

\begin{abstract}
We intend to discuss adolescent domestic labour using a gender relationship perspective while linking it to the categories of social class, ethnicity and intergenerationality. We use data of a study conducted in Natal (RN), that points out that young women initiate work early in their lives thereby accumulating school and job tasks. The working conditions are unequal, exemplified by low pay, extensive work periods, and night shifts which is prohibited for those under 18 years of age. This type of work is undervalued, routine, and unstimulating. It reproduces many social conflicts, especially those related to gender, for it is a form of perpetuating the designation of the domestic space to the feminine figure thereby reproducing the sexual division of labour. In spite of that, however, this type of work has a positive meaning for these young women. They view it as a form of social ascension, of gaining autonomy, and of helping their families that live in the interior of the state.

Keywords: Domestic labour; Adolescent; Women; Gender relationships; Private sector.
\end{abstract}

\section{Introdução}

Este artigo pretende discutir o trabalho doméstico remunerado exercido por adolescentes do sexo feminino que moram com os patrões na cidade de Natal (RN). O trabalho doméstico, remunerado ou não, é uma realidade na vida de milhares de meninas e mulheres no Brasil. É a forma de trabalho mais comumente encontrada entre mulheres das camadas populares e tem uma forte vinculação com o papel que estas ocupam na sociedade. Nesse sentido, há uma estreita relação entre trabalho doméstico e a reprodução da pobreza e das relações de gênero. Nosso objetivo foi conhecer as condições sob as quais o trabalho se efetiva e o sentido atribuído pelas jovens acerca dessa atividade em suas vidas, ressaltando aspectos como sua vinculação à reprodução de relações de classe, de geração e, principalmente, de gênero.

\section{O trabalho doméstico adolescente: o panorama de uma realidade}

O trabalho doméstico realizado por adolescentes é uma forma de inserção precoce ${ }^{1}$ no mundo do trabalho, muito comum dentre as jovens do sexo feminino. $\mathrm{O}$ número mundial de crianças e adolescentes que trabalham é impreciso, girando em torno de 200 milhões. Essa imprecisão se deve à falta de dados em diversos países acerca de muitos ofícios que não são considerados como atividades de trabalho, por serem "invisíveis", ou seja, há uma dificuldade de identificá-los, uma vez que são realizados no setor informal da economia, como é o caso desse modo de trabalho aqui focalizado.

No Brasil, segundo a PNAD/2001, existem mais de 491.441 crianças e adolescentes de 10 a 17 anos como empregados domésticos (IBGE, 2002), dos quais

\footnotetext{
* Agradecimento ao apoio financeiro recebido da CAPES.

Endereço para correspondência:

* E-mail: munichsantana@bol.com.br

** E-mail:magdad@uol.com.br

${ }^{1}$ Quando há referência à palavra precoce, estamos nos referindo aos indivíduos com menos de 18 anos de idade.
} 
$71 \%$ têm entre 15 e 17 anos e 93\% são meninas. Porém, esse número pode estar camuflando uma quantidade bem maior, tendo em vista que muitos não assumem a utilização dessa precoce mão-de-obra em suas casas, principalmente quando não há uma remuneração efetiva.

A realização de atividades domésticas exercidas por adolescentes é uma forma de trabalho muito encontrada em diversos países do mundo e também no nordeste brasileiro. No Rio Grande do Norte (estado no qual se realizou o estudo), foram registradas 6.859 crianças e adolescentes, todas mulheres, trabalhando como empregadas domésticas, representando 8,4\% da população de trabalhadores com menos de 18 anos, principalmente, na faixa etária de 15 a 17 anos (IBGE, 2002).

No nordeste como um todo é comum que as famílias das capitais busquem crianças da zona rural para "ajudar" nas atividades domésticas ou para "brincarem" com seus filhos, exercendo a função de babás. Na maior parte das vezes, essas crianças ou adolescentes começam a trabalhar sem receber remuneração ou, quando recebem algum salário, está abaixo do mínimo nacional, funcionando como empregados irregulares.

As condições de moradia e de horas de trabalho dependem de seus empregadores e, muitas vezes, são impróprias. As crianças dormem onde podem, comem o que determinam seus patrões, estão sujeitas a humilhações, além de, quase sempre, terem negado o direito de freqüentar a escola (UNICEF, 1997). Todas essas com-dições irregulares podem ser fatores de risco psicológico e social, podendo ocorrer até maus tratos e abuso sexual. Dessa forma, considera-se que essa pode ser uma das piores formas de trabalho infanto-juvenil por esses indivíduos estarem expostos a situações de risco para sua segurança, saúde e moralidade.

Outro aspecto importante é que o trabalho doméstico está diretamente relacionado com a raça negra. Diante da história de escravidão na época colonial, Melo (1998) informa que após a abolição da escravatura (final do século XIX), o trabalho doméstico tornou-se uma das maiores formas de trabalho feminino. Entretanto, apesar de ser uma atividade muito encontrada, é desvalorizada e considerada de pouca importância na maioria das sociedades modernas. Ou seja, é uma atividade subestimada por não ser reconhecida como um trabalho; isolada, por ser realizada na unidade doméstica; invisível do ponto de vista econômico (já que ocorre no setor informal), psicológico e ideológico, sendo também consumida na mesma proporção em que é realizada. Em outras palavras, durante todo o dia, a empregada está realizando tarefas que precisam ser constantemente refeitas, corroborando sua desvalorização, como é o caso dos trabalhos de limpeza (Preuss, 1996).

Alguns estudos apontam que as crianças e as adolescentes encontram-se muitas vezes em situação irregular na casa de seus patrões, já que elas, quando transferidas de um lugar para outro, de jurisdição diferente (como é o caso de garotas que vêm do interior do estado), não têm consigo a regularização de sua situação de guarda junto à Vara da Infância e Adolescência, o que seria exigido conforme a legislação vigente no Estatuto da Criança e do Adolescente - ECA (Dantas, 2000).

Ainda é observado sobre as meninas trabalhadoras domésticas que sua situação escolar é muito preocupante, pois, quando são comparadas com as meninas que trabalham em outra forma de atividade, percebe-se que 32,8\% não estudam, enquanto dentre as outras trabalhadoras, apenas $17 \%$ estão fora da escola. Esse quadro agrava-se ainda mais no nordeste brasileiro, em que 39,2\% das trabalhadoras domésticas, entre 10 e 16 anos, estão fora da escola (Sabóia, 2000). Além disso, as empregadas domésticas possuem uma tendência de apresentar menos anos de estudos do que as não-trabalhadoras ou as que exercem outras atividades. Sabóia (2000) afirma que aos 14 anos, quando a jovem deveria estar concluindo o ensino fundamental, apenas 9,8\% das trabalhadoras domésticas o conseguem, enquanto as que trabalham em outras atividades e as que não trabalham estão, respectivamente, com índices de $20 \%$ e $26 \%$ de conclusão do ensino com sete anos de escolarização.

O emprego doméstico cresce de importância na vida da mulher na medida em que a menina torna-se mais velha. Isso é apontado por Sabóia (2000), ao analisar dados da PNAD/1998, em que, dentre as meninas com 10 anos, apenas $4 \%$ das trabalhadoras são domésticas. $\mathrm{Na}$ idade de 12 anos, esse percentual sobe para $11,2 \%$ e, aos 14 , atinge 25,5\%. Com 16 anos, chega-se a um ápice, em que $31,9 \%$ das trabalhadoras existentes são empregadas domésticas. De um modo geral, a mão-de-obra feminina na faixa dos 10 aos 16 anos é composta por 22,6\% de trabalhadoras domésticas, demonstrando a importância desse emprego para as mulheres adultas e meninas pobres do Brasil.

É claro que nem sempre o trabalho doméstico é sinônimo de exploração da mão-de-obra, tendo em vista servir como uma ponte para outras formas de trabalho mais valorizadas socialmente. A menina pode ter acesso a seu primeiro emprego e dar continuidade à educação, desde que lhe sejam garantidas as condições de trabalho tanto juridicamente quanto humanamente, sendo tratada e respeitada como uma profissional. $\mathrm{O}$ trabalho doméstico de adolescentes é encontrado em famílias cuja condição de pobreza as expulsou da zona rural na busca de melhores condições de vida nas zonas urbanas e capitais e, por isso, é possível encontrar na casa dos patrões um lar melhor que o anterior, pelo menos no que se refere à alimentação e moradia. 
Conhecer as condições de trabalho doméstico realizado por adolescentes residentes na casa dos patrões foi o ponto de partida para a realização desta pesquisa, já que consideramos que essas condições podem oferecer, segundo discussão anteriormente realizada, maiores riscos às adolescentes, quanto à escolarização (abandono e atraso escolar), a relacionamentos interpessoais (isolamento, falta de amigos e namorados), a risco de abusos sexuais e humilhações, dentre outros.

Esta forma de trabalho tem uma forte relação com a história pessoal e social da figura feminina, tendo em vista que ela é, muitas vezes, responsável pelo que ocorre no âmbito privado de uma família e está ligada à domesticidade e reprodução social. Assim, buscamos conhecer um pouco a história da mulher, visitando conceitos de gênero que embasam teoricamente este estudo.

\section{A mulher e as relações de gênero no espaço doméstico}

A domesticidade é um componente associado à mulher e à sua história. É um componente tão fortemente vinculado à figura feminina, por sua importância no espaço doméstico, que se confunde e se funde num mesmo aspecto, ou seja, ao analisar a história das mulheres, o espaço privado mostra-se como uma condição indispensável de análise (Andrade, 2000).

A idéia de que o espaço doméstico é destinado à mulher é uma construção sócio-histórica em que os aspectos biológicos deram suporte ideológico para essa afirmação. A mulher foi reconhecida como a "rainha do lar" e ainda o é. Basta observar as propagandas que são feitas acerca do papel feminino na família e na sociedade. A mídia divulga uma imagem de mulher como aquela que sabe, dentre outras coisas, escolher a melhor comida e o melhor sabão. Essa forma de se falar da mulher está impregnada de um saber que vem sendo construído a algum tempo, associando a mesma a uma domesticidade difícil de ser modificada ou desconstruída. Não é suficiente apenas olhar o que ocorre na unidade doméstica, mas também o modo como o poder simbólico masculino perpetua-se na sociedade (Bourdieu, 1996).

Essa domesticidade nem sempre foi vista como desvalorizada, foi sendo construída enquanto tal ao longo da história. É importante reconhecer que a divisão entre espaço público e privado se torna menos rígida com a entrada da mulher no mercado de trabalho, no espaço público, mas ainda é claramente visível. O capitalismo, como movimento econômico e social, sempre esteve ancorado na teoria do patriarcado, tão forte em épocas passadas, para explicar e justificar as diferenças existentes entre homens e mulheres na sociedade. Tal perspectiva ainda é uma realidade na contemporaneidade.
Aguiar (1997), em uma discussão sobre a perspectiva feminista e o conceito de patriarcado, afirma que ele é caracterizado por

\section{um sistema de normas baseado na tradição, quando as decisões são tomadas de uma determinada forma, porque isto sempre ocorre de um mesmo modo. Outro elemento básico da autoridade patriarcal é a obediência ao senhor, além do que é devotada à tradição. (p. 171)}

Entretanto, não foi somente a ideologia do patriarcado que veio cristalizar o papel da mulher em casa. O sanitarismo, movimento existente no final do século XIX, também construiu e consolidou formas de pensar o lugar social da mulher no lar. As mulheres tinham a responsabilidade de cuidar e conservar a família, buscando concentrar seus membros em casa. Elas contribuíam ativamente com as políticas sanitaristas aliando-se aos médicos e atuando como agentes de saúde. Assim, tanto as mulheres do povo (que proibiam as idas dos homens aos cabarés e às crianças de ficarem nas ruas), quanto as burguesas (que eram guardiãs do lar, mantendo a continuidade das atividades familiares e sociais) garantiam a ordem em seus lares. De modo geral, exerciam funções que mesclavam proteção e educação (Donzelot, 1986).

Freire (1970) afirma que, antes do movimento sanitarista, o espaço doméstico era determinado como da mulher, por ela ser o "sexo frágil", necessitando ser protegida no lar. Com as políticas higienistas dos séculos XIX e XX, isso ocorre por outros motivos. A partir de então, começa a se difundir o pensamento de que as mulheres têm que garantir a perpetuação da família e garantir o poder do Estado.

Nesse sentido, segundo Pena (1981, citado por Bruschini, 1990), o trabalho exercido em casa pela mulher/ esposa passa a se constituir o cerne da opressão feminina, na medida em que está incluído em um mecanismo pelo qual os serviços são prestados gratuitamente, tendo ela como responsável. O trabalho doméstico faz parte do cotidiano da mulher e está na base das relações entre o masculino e o feminino. Este trabalho, não remunerado, não é reconhecido como trabalho pelo modo de produção capitalista, e sim como uma atribuição feminina para reprodução da sociedade (Gouveia \& Camurça, 1997).

Apesar disso, a mulher vem ganhando espaço na esfera pública e aumentando as conquistas femininas, rumo à emancipação. Isso acaba tendo um impacto na sociedade, que é sentido principalmente pelas mudanças que levaram homens, mulheres e crianças a redefinirem os papéis na família, e assim, fazer com que ela continue perpetuando-se. As mulheres, cada vez mais, foram saindo do âmbito privado para estudar, ter uma 
formação profissional e, acima de tudo, trabalhar. Ao contratarem trabalhadoras domésticas para repassarem as tarefas que outrora eram delas, estão de certa forma reproduzindo a idéia de que o espaço privado é de domínio do feminino, ao invés de transformá-lo em uma responsabilidade de toda a família.

Contratar empregadas para realização de trabalhos domésticos é uma prática encontrada em muitos países em desenvolvimento como o Brasil. No nordeste brasileiro, região que está marcada por idéias próprias do patriarcalismo, e que tem uma clara herança escravagista, essa forma de contratação de serviços ainda é muito disseminada. Inclusive, é nessa região que se encontra o maior percentual de crianças e adolescentes no trabalho doméstico, como referido anteriormente (Sabóia, 2000).

Preuss (1996) aponta que uma mulher trabalhando para outra mulher é uma forma clara de manter a divisão sexual do trabalho e as relações de gênero dentro de uma casa:

\section{O emprego doméstico serve como um amenizador de crises na medida que, enquanto as mulberes se complementam na execução do trabalbo doméstico, fica garantido o pequeno envolvimento do homem nessas tarefas, mantendo- se a tradicional divisão sexual do trabalho e o conco- mitante dominio masculino no espaço público. (p. 55)}

A relação entre essas duas mulheres, patroa e empregada, é, muitas vezes, desprovida de fronteiras rígidas, o que favorece uma vinculação ambivalente e um aspecto antiprofissional ao trabalho doméstico. Preuss (1996) se refere a essa relação como assimétrica, tendo em vista que uma delas tem uma empregada e que a outra é uma empregada. Nessa relação, haveria uma contradição entre poder e afeto desenvolvidos entre elas. Sem dúvida, há um conflito de classe entre essas duas mulheres e, juntas, acabam reproduzindo a divisão sexual do trabalho e as relações de gênero.

Recorremos ao conceito de relações de gênero para melhor entender esta temática do trabalho doméstico e nos aproximarmos da realidade da trabalhadora adolescente. Meyer (1996) aponta que o gênero "é a instância onde e no meio da qual os seres humanos aprendem a se converter em e a se reconhecer como homens e mulheres, nos diferentes contextos históricos, culturais e sociais" (p. 48). Afirma, ainda, que discutir gênero é ir além do lugar onde as subjetividades sexuadas são produzidas. Como discurso, o gênero produz e é produzido, organiza e é organizado e, por isso, atravessa, modula e regula o próprio contexto social. Ele está intrínseco na constituição e na operação de símbolos, de doutrinas, das instituições e organizações sociais e, também, nos processos de construção da subjetividade.
Nesse contexto, resgatamos a produção teórica do grupo francês de estudos sobre as mulheres (GEDISST), ${ }^{2}$ as quais entendem a divisão sexual do trabalho como o motor das desigualdades entre os sexos, ou seja, a partir da divisão social e sexual do trabalho aparecerão, com mais clareza, as diferenças entre homens e mulheres (Oliveira, 1999).

Como já mencionamos o conceito de gênero é recuperado a partir da divisão sexual do trabalho. Essa divisão não se data no capitalismo, ela antecede esse modo de produção. Porém, vale destacar que foi a partir deste sistema econômico-político que adquiriu status diferenciados e passa a ser entendida e (des)valorizada, tal como é hoje em dia. Enfim, de um lado está o espaço público da produção de bens associado ao masculino; do outro, temos o espaço da reprodução, o qual se faz na esfera privada, sendo reconhecido como "naturalmente" feminino e apropriado à produção de seres humanos (Combes \& Haicault, 1986). Porém esta domesticidade feminina foi quebrada com a entrada da mulher no mercado de trabalho e na produção de bens. $O$ que não significa dizer que o trabalho doméstico deixa de ser uma "obrigação" da mulher, quando contrata uma empregada.

A divisão sexual do trabalho não esgota a problemática das relações sociais entre homens e mulheres na medida em que elas comportam construções culturais e históricas independentes e complementares. Isso quer dizer que as relações entre homens e mulheres são vividas e pensadas como sendo relações de gênero, ou seja, relações entre o que é definido como masculino e como feminino. Autoras como Hirata e Kergoat (1994) dizem que a divisão sexual do trabalho é um dos lócus das relações de gênero, denominando então tais relações como relação social de sexo (Lobo, 1992).

Ampliando a perspectiva acima, quando se entende um sistema de gênero como sistema de poder resultante de um conflito social, amplia-se também o entendimento do gênero para além do sexo feminino ou masculino. Em outras palavras, pode existir uma relação de gênero entre dois grupos que estejam reproduzindo conflitos entre o masculino e o feminino e esses dois grupos podem ser representados por pessoas do mesmo sexo. Quando se afirma que pode estar existindo uma relação de gênero entre duas mulheres, como no caso de patroas e empregadas, ou entre dois homens, na realidade, o que está em jogo é a reprodução das desigualdades entre o masculino e o feminino.

No caso da trabalhadora doméstica que está ocupando o lugar que outrora foi da mulher/esposa, ela, além de reproduzir um papel reconhecido como feminino, trava relações, muitas vezes, conflituosas com

\footnotetext{
${ }^{2}$ Grupo de estudos sobre a divisão social e sexual do trabalho do Centre National de Recherche Scientifique (CNRS).
} 
suas patroas. A patroa acaba ocupando um lugar contraditório em relação à perspectiva de gênero, pois, ao mesmo tempo em que galga no mundo público e diminui as diferenças sociais com os homens no mundo privado, termina por reproduzir um lugar desvalorizado para a mulher que trabalha para si, em sua própria casa. Compartilhamos as idéias de Saffioti (1994) quando chama a atenção para o que entende como relações de gênero e de poder:

\section{Conceber gênero como uma relação entre sujeitos historica- mente situados é fundamental para demarcar o campo de batalha e identificar o adversário. Nestas circunstâncias, o inimigo da mulher não é o bomem nem enquanto individuo, nem como categoria social, embora seja personificado por ele. O alvo a atacarpassa a ser, numa concepção relacional, o padrão dominante da relação de gênero. Diferentemente do que se pensa com freqüência, o gênero não regula somente as relaçōes entre homens e mulheres, mas normatiza também relações homem-bomem e relações mulher-mulher. Deste modo, a violência cometida por uma mulher contra outra é tão produzida pelo gênero quanto a violência per- petrada por um homem contra uma mulher. (p. 275-276)}

Articulando as duas concepções, entendemos que contratar empregadas domésticas não é um problema se a elas fossem garantidos todos os direitos usufruídos por um outro trabalhador qualquer. Acontece que, ao se contratar essa mão-de-obra, leva-se juntamente toda uma história de desvalorização que perpetua as diferenças entre o público e o privado, entre homens e mulheres. Além disso, concordamos com o que é proposto por Saffioti (1994) quando diz que gênero é uma das formas de articular poder junto com classe social e etnia, sendo, portanto, questões indissociáveis.

Além desses dois aspectos, chamamos atenção para a questão geracional, já que a trabalhadora em questão é uma adolescente que pode estar vivendo conflitos de identificação com a figura da patroa. Quanto a este último aspecto, destacamos que essa jovem trabalhadora está no momento temporal entre a infância e a vida adulta, no qual estão se consolidando vivências e projetos de vida futura. É justamente nesta fase que se busca conhecer como o trabalho doméstico lhe afeta, bem como conhecer o sentido deste trabalho em suas vidas, percebendo se esta é uma forma de trabalho exploradora ou não.

\section{Aspectos metodológicos da investigação com adolescentes trabalhadoras}

Sujeitos

A pesquisa de campo foi realizada com 332 adolescentes do sexo feminino, entre 12 e 17 anos, freqüentadoras de 28 escolas públicas estaduais e municipais, alunas dos cursos do ensino de Educação para Jovens e Adultos - EJA (antigo supletivo) - turno noturno, na cidade de Natal (RN). A escolha do curso noturno deveu-se ao fato de as meninas exercerem suas atividades, na maioria das vezes, no período diurno, numa carga horária inespecífica e larga (Sabóia, 2000), restando, como tempo disponível, para estudarem, o turno da noite.

\section{Procedimentos e instrumentos}

Ao entrarmos nas escolas não tínhamos como identificar antecipadamente quem era empregada doméstica ou não. Para tanto, aplicamos um questionário identificador de atividades ocupacionais. Com esse instrumento constatamos que, das 332 adolescentes participantes, 154 eram trabalhadoras domésticas. Além desse instrumento, realizamos entrevistas com 14 adolescentes trabalhadoras domésticas que residem com os patrões. A entrevista foi organizada com base em nove temas centrais: identificação, história familiar e escolar; histórico do trabalho; condições de trabalho doméstico; condições de vida; relações interpessoais; autopercepção; saúde e expectativa de vida futura. Tal roteiro foi baseado no manual de investigação e ação sobre o trabalho doméstico de crianças da Anti-Slavery International (Black, 1997).

$\mathrm{O}$ objetivo da investigação foi conhecer sob quais condições trabalhavam essas jovens e qual era o sentido do trabalho em suas vidas. Ademais, procuramos, pelos discursos, identificar questões relativas à reprodução das relações de gênero no contexto do trabalho doméstico. Para entender tal sentido, optou-se pela metodologia das práticas discursivas proposta por Spink (2000), numa abordagem qualitativa de entender e fazer pesquisa científica.

\section{Resultados}

Vamos centrar nossa análise nos resultados das entrevistas realizadas, nas condições e sentido atribuído pelas jovens ao trabalho que realizam. Para os dados de identificação, vamos apresentar resultados relativos às adolescentes trabalhadoras domésticas $(n=154)$, especialmente do subgrupo que reside com os patrões $(n=116)$. Esse grupo registrou idades que variavam entre 14 e 17 anos, representando 39\% do grupo total de todas as jovens que responderam ao questionário nas escolas. Esse é o maior grupo de trabalhadores, confirmando a forte presença dessa atividade de trabalho entre as adolescentes das escolas noturnas do curso de EJA - supletivo de Natal.

Características gerais e condições de trabalho

Dentre essas trabalhadoras, a maior parte situa-

Psico-USF, v. 10, n. 1, p. 93-102, jan./jun. 2005 
se em torno dos 16 e 17 anos (71\%), corroborando os dados trazidos por Sabóia (2000) de que a maior taxa de adolescentes trabalhadoras domésticas situa-se por volta dos 16 anos, com uma taxa de emprego de 31, 9\%.

Quase todas as adolescentes desse grupo moram perto da escola, sendo o lugar de moradia de seus familiares em bairros mais populares ou no interior do estado. Todas moram no local de trabalho, podendo exercer essa atividade para familiares - irmã $(\mathrm{o})(\mathrm{s})$, primas, tio(a)(s) e madrinhas - totalizando $18 \%$ delas, ou para patrões sem nenhum grau de parentesco (82\%).

Dentre as adolescentes pesquisadas, $78 \%$ têm a cor de pele entre morena e negra, acentuando uma forte tendência étnica nessa profissão, justificando sua relação com a história escravagista. Tal fato foi afirmado por Bento (1995), quando ressalta que as trabalhadoras domésticas são em maioria negras, com um número três vezes maior que o de mulheres brancas.

Elas têm uma precoce inserção laboral, já que começaram a trabalhar com idade entre 10 e 14 anos. O emprego foi arranjado por parentes ou conhecidos da família e o contrato foi feito, geralmente, com a própria jovem ou com sua mãe. Essas jovens vêm do interior do estado do Rio Grande do Norte ou da Paraíba, ou de bairros de periferia, para trabalhar no intuito de conseguir seu próprio dinheiro. As condições de vida no lar de origem estimulam as jovens a procurar um melhor emprego na capital do estado e, na maior parte das vezes, não são as únicas filhas da família que saíram em busca de emprego como empregadas domésticas.

As famílias dessas 14 jovens entrevistadas, na sua maioria, são chefiadas por mulheres $(n=09)$, seja porque estão separadas de seus companheiros, seja porque estão viúvas. A literatura do campo aponta que, nas famílias chefiadas por mulheres, as crianças começam a trabalhar mais cedo, principalmente quando são famílias numerosas. As famílias de nossas entrevistadas são numerosas, tendo em média seis filhos cada. Famílias numerosas também se configuram como um dos motivos que aumentam a pobreza e incentivam o trabalho infantojuvenil, visto que os adolescentes precisam ajudar no orçamento familiar (Cervini \& Burger, 1996).

As jovens afirmam que querem trabalhar e ganhar dinheiro para comprar objetos pessoais e não dar mais despesas aos pais. Porém, algumas dizem que necessitam trabalhar não somente para elas, mas para ajudar seus familiares, mandando-lhes periodicamente uma quantia de dinheiro. Apenas uma das jovens fica com o dinheiro todo para si, mesmo porque não conta com o apoio de ninguém de sua família.

Quanto ao aspecto financeiro, muitas afirmam que a parte boa do trabalho é ter seu próprio dinheiro, comprar suas coisas, "coisinhas de mulher" (O., 15 anos) e algumas apontam a parte financeira como a única coisa boa deste trabalho. É bom lembrar que apenas duas delas ganham um salário mínimo completo.

O caráter reprodutivo do trabalho doméstico está muito bem explícito na fala das jovens. Elas não produzem nenhum bem de consumo, mas permitem que a sociedade se reproduza. Saffioti (1994) afirma que essa forma de trabalho, justamente por não produzir bens com valor de troca, não é valorizada e, muitas vezes, é desconsiderada pelo capital. Todavia, esta atividade do trabalho doméstico remunerado é a que possibilita aos patrões uma produção no mercado de capitais, tornandose imprescindível ao modo de produção capitalista.

Outro aspecto percebido dentre as trabalhadoras é a rotatividade de emprego. Quanto a isso, Motta (1989) afirma que a empregada doméstica tem um "turnover" elevado, tendendo a abandonar o emprego na medida em que sente os primeiros sinais de desconforto psíquico. Isso quer dizer que a rotatividade é muito comum na vida dessas trabalhadoras. Por um lado, essa mudança de empregos é ruim, pois faz com que a jovem tenha que se adaptar a cada casa que chega. No entanto, ao mesmo tempo, é isso que acaba protegendo a empregada doméstica, na medida em que ela, ao perceber as dificuldades de trabalho, prefere sair ou abandonar o emprego. $\mathrm{O}$ fato de passar todo o dia trabalhando e morando com a família contratada faz com que, muitas vezes, esteja mais suscetível às coisas desagradáveis que outros tipos de trabalhadores.

Quando perguntadas com quem moravam, em geral as jovens referiram-se às patroas e não aos patrões, demonstrando que a vinculação de trabalho ocorre mais com outra mulher, a dona da casa, o que acaba corroborando as informações trazidas por Preuss (1996) de que, nesse trabalho, tem-se uma mulher trabalhando para outra mulher. Ou seja, uma mulher (mesmo que haja outros membros na família contratante) acaba por contribuir e ser responsável pela contratação e reprodução do lugar doméstico da figura feminina. Como o espaço doméstico é reconhecidamente feminino (Andrade, 2000), nada mais esperado que o contrato deste trabalho seja realizado entre mulheres.

Dentre as tarefas desempenhadas, existem duas atividades básicas, uma que diz respeito às atividades de cuidado com a casa e outra que diz respeito aos cuidados com algum membro da família (crianças ou idosos). Uma terceira forma de atividade desempenhada seria a que acumula os dois tipos de trabalho anteriormente descritos.

Notamos que quase todas as adolescentes cuidam da casa (99 jovens do grupo de 116), independente de realizarem outras atividades. Assim, 85\% desse grupo desenvolve atividades como arrumar, lavar, passar, cozinhar, para que a família contratante possa reproduzir-se 
e inserir-se no mercado de trabalho. Elas possibilitam que tais famílias possam produzir bens de consumo ou de troca, mesmo ao custo de um trabalho que não está sendo valorizado adequadamente.

Em relação à jornada de trabalho, detectamos que um grande número de jovens trabalha de dois a três turnos, sejam eles completos ou não. São poucas as adolescentes que trabalham apenas um turno, e quando isso acontece, normalmente é no da manhã. $\mathrm{O}$ maior número de meninas trabalha 2 turnos $(59 \%)$ e $33 \%$ delas trabalham até 3 turnos, realizando atividades de trabalho antes e depois de irem à escola. Quando observamos os turnos trabalhados em relação ao tipo de atividade que desempenham, flagrantemente percebemos que as adolescentes que cuidam da casa têm um maior percentual de trabalho noturno $(36 \%)$, e as que menos apresentam trabalho nesse horário são as que apenas cuidam de criança ou idoso.

O mais grave é que dentro dessa categoria profissional, de um modo geral, não há definição de jornada de trabalho, o que acaba por dificultar a fiscalização das horas trabalhadas pela adolescente. Diante disso, essa jovem pode participar do trabalho à noite num horário que, por lei, é proibido para menores de 18 anos (ECA, 1994, art. 67). Isso indica que as jovens trabalhadoras domésticas estão exercendo as atividades em condições trabalhistas desfavoráveis.

\section{Os sentidos do trabalho realizado pelas adolescentes}

Pelos discursos das adolescentes foi possível observar que o trabalho realizado apresenta tanto aspectos positivos quanto negativos. Entendemos que tais aspectos estão diretamente relacionados ao tipo de vínculo que se estabelece entre patroa-empregada. Na contratação da trabalhadora doméstica, dois pontos são primordiais: um que diz respeito aos aspectos legais e trabalhistas, e outro relativo à qualidade da relação estabelecida entre adolescente trabalhadora doméstica e a patroa/adulta.

Assim, ressaltamos que, em se tratando das condições em que o trabalho é realizado pelas adolescentes, estas apresentam uma conotação negativa, ao passo que o sentido, a vivência do trabalho, tem uma conotação positiva. Ou seja, percebemos que as condições do trabalho doméstico são desfavoráveis na maior parte dos casos, com baixos salários, sem garantia de direitos trabalhistas como carteira assinada, direito às férias e folga semanal e, por isso, configura-se, no nosso ponto de vista, como uma forma de trabalho explorado.

A relação patroa e empregada é um outro aspecto importante que faz com que esta exploração se efetive, tendo em vista que pode estar camuflando uma forma hierarquizada de relacionar classe social (etnia), gênero e geração, ou seja, há uma relação de dominação entre estes dois personagens. Assim, quando a jovem tem uma boa relação com os patrões, é bem cuidada por eles, o não-cumprimento das leis trabalhistas por parte dos patrões fica ocultado, esquecido. Esta relação, quando se estabelece de forma amigável, passa a ser mais importante para a adolescente trabalhadora do que o cumprimento de seus direitos trabalhistas e de cidadã. Do lado dos patrões, parece que o fato de tratá-la como "sendo da familia" é a forma mais "barata" de contratar serviços domésticos sem arcar com as responsabilidades legais.

No que se refere à qualidade da relação, esta é considerada boa quando a jovem se submete aos patrões, às normas da casa e à disciplina aí implantada. Assim posto, a empregada vive na condição de refém de sua própria submissão, tendo em vista que, quando apresenta comportamentos de insubmissão, ela acaba sofrendo represálias e estabelecendo conflitos com os patrões, que sempre controlam sua vida, seja quanto aos horários de chegada e de saída, seja quanto às folgas e amizades.

Com tal análise, não defendemos que a relação entre patroa e empregada deva ser conflituosa. O que queremos é problematizar o fato de que muitas vezes este tipo de relação pode camuflar formas maiores de exploração, que podem ser justificáveis ou desculpáveis pelo bom trato que é dado à adolescente, e isso é muito comum quando a patroa expressa que a empregada é "quase da família" ou "quase uma filha".

O trabalho doméstico na vida das adolescentes está impregnado de preconceitos e, conseqüentemente, é desvalorizado tanto por parte da sociedade quanto pelas próprias jovens, o que é percebido quando as mesmas têm dificuldade de assumir o emprego no qual trabalham. Freqüentemente sentem vergonha, por mais que isso não seja reconhecido como preconceito por elas na medida em que representa uma continuidade da vida que elas desvalorizam. Isso também é percebido em razão de a grande maioria não pretender permanecer nessa forma de trabalho, desejando outros empregos que possam trazer mais dinheiro e/ou valorização social.

Porém, o trabalho doméstico não se resume a aspectos negativos e de exploração, segundo as adolescentes. Existem fatores positivos que estão relacionados com a realidade da própria jovem, tendo em vista que esse trabalho possibilita que ela saia do interior do estado, onde muitas vezes passa por situações de vida difíceis, de extrema pobreza e desarranjo familiar. Com esse trabalho a adolescente tem a possibilidade de contribuir no orçamento familiar, enviando dinheiro para seus pais; ela passa a gerir sua renda e seus gastos pessoais, não onerando sua família e desenvolvendo autonomia. Além disso, é uma possibilidade de crescer profissionalmente para outros ramos de atividade, já 
que a freqüência à escola pode ser um canal aberto para a especialização da sua mão-de-obra. A escola também tem uma função muito importante, que é a de socializar a jovem trabalhadora e que acaba por amenizar o isolamento social em que vive.

Dessa forma, poderíamos dizer que o sentido do trabalho produzido pelas jovens entrevistadas é mais positivo do que negativo, isto é, o trabalho doméstico explora a jovem trabalhadora, mas apesar disso é percebido como uma possibilidade de ganhar dinheiro e mudar de vida. Caso fossem respeitados seus direitos trabalhistas e humanos, este trabalho poderia servir como uma forma digna de passagem para algo mais qualificado no futuro. Quando apenas os aspectos negativos sobressaem, acaba por reproduzir a pobreza e a desvalorização historicamente ligadas a ele.

A contradição evidente é que, apesar de seu sentido positivo, nenhuma delas quer continuar nesse emprego. Elas afirmam que querem desenvolver outro tipo de atividade como projeto de vida futuro, porém, percebemos uma tendência a eleger profissões reconhecidas como femininas, tais como de professora, enfermeira, psicóloga, pediatra, costureira, aeromoça, atriz, garçonete, secretária de escritório, telefonista, dentre outras. Isso reforça a tendência de que as mulheres se envolvem em atividades socialmente menos valorizadas, independente de serem de nível superior ou técnico. Tendo em vista os aspectos acima relacionados, pensamos que, para entender o trabalho doméstico, é primordial que busquemos entender a própria história da mulher na sociedade em que vivemos, já que este trabalho tem uma forte relação com a figura feminina.

O aspecto geracional é outro fator importante na determinação do sentido positivo deste trabalho, pois as jovens começam a trabalhar numa idade muito precoce, muitas vezes na infância, o que acaba por atribuir aos aspectos afetivos da relação com a patroa uma força ainda maior. Muitas vezes, a adolescente vivencia conflitos com a patroa, reproduzindo os atritos próprios dessa fase de vida em relação aos familiares, especialmente nas situações em que a patroa assume o papel substituto de mãecuidadora. Embora não seja nosso objetivo neste trabalho desenvolver mais profundamente a análise desta questão, é importante apontarmos que o aspecto geracional é um ponto importante na relação entre patroa e empregada.

As adolescentes expressam claramente o aspecto ambivalente que marca a relação. Elas sentem, por exemplo, que as patroas controlam seus horários de chegada e saída, assim como mostram uma preocupação, muitas vezes excessiva, quanto às suas relações amorosas e de amizade. Algumas adolescentes entendem isso como uma demonstração de cuidado e de proteção próxima do que seria esperado da figura materna. Tal situação é reforçada pelo discurso de que são membros da família e merecem esse tipo de atenção. Assim, tais cuidados são valorizados e desejados. Porém, essas mesmas práticas são sentidas por outras jovens, e até para as anteriores em momentos diferentes, como de vigilância e controle, como um boicote à sua liberdade. Portanto, assumem um sentido negativo. As jovens argumentam que não admitem que uma pessoa que não é da família controle seus passos, já que não estabelecem esse tipo de relação nem com a própria mãe.

Outra situação muito referida envolve aspectos como estudo e remuneração. Novamente a relação entre ambas é atravessada por forças paradoxais. Algumas patroas exigem a permanência da adolescente na escola como condição para manutenção do emprego. Outras, ao contrário, exigem dedicação exclusiva ao trabalho, sem direito de freqüentar a escola. Ou seja, a relação está, há todo momento, perpassada por sentimentos de cuidado e controle, atenção e rechaço, respeito e desvalorização, por afeto e desafeto. Daí, a emergência de muitos conflitos entre patroa-empregada, sustentados por expectativas contraditórias em relação ao papel de cada uma. Porém, é esse pólo positivo da relação (sentimento de ser cuidada, bem tratada, da família, etc.) que sustenta a exploração do trabalho e o não-cumprimento dos deveres trabalhistas por parte dos patrões, com a "concordância" das adolescentes.

\section{Finalizando: $\mathrm{O}$ trabalho doméstico pode ter dois sexos?}

Resgatamos a famosa frase feminista que afirma que a classe operária tem dois sexos (Hirata \& Kergoat, 1994). No nosso caso, perguntamos se o trabalho doméstico pode ter dois sexos, ou seja, se ele pode ser exercido da mesma forma por homens e mulheres. Percebemos, então, que o trabalho pode até ser exercido pelos dois sexos, mas é mais comum encontrar mulheres, até porque este foi o espaço resguardado e garantido para elas em anos de história, mesmo diante de tantas mudanças de papel na sociedade.

Os aspectos que reforçam que o "lugar da mulher é em casa" são os que perpetuam esse tipo de trabalho como feminino, e que justificam que se contratem trabalhadoras domésticas. Tais aspectos são percebidos dentro do processo de socialização em que as mães, irmãs ou outras mulheres do núcleo familiar mais próximo ensinam a desenvolver tarefas como cozinhar, arrumar a casa, cuidar de irmãos, muito precocemente, antes mesmo de começar a vida laboral, principalmente nas familias mais desfavorecidas e chefiadas por mulheres. Segundo Madeira (1997), a execução de afazeres domésticos na casa dos pais é o que prepara a jovem para este tipo de 
atividade e isso é confirmado pelas adolescentes entrevistadas. Além do aprendizado familiar, o ensino das tarefas também pode ser repassado pela patroa no momento de contratação.

O homem, em geral, está afastado dos processos de manutenção cotidiana de uma casa. Uma das entrevistadas de 16 anos explica como o homem exime-se de exercer a atividade doméstica, porque, em geral, essa atividade mexe com a virilidade masculina. É algo transmitido por meio do convívio com as mães e com as esposas, perpassando para as filhas. Ela diz: "Os homens, hoje, ainda são muito preconceituosos. Por que o homem não cuida da casa que é dele? $\mathrm{E}$, às vezes, o homem não aceita ser tratado assim. A esposa, por exemplo, pede pra ele fazer alguma coisa e eles não querem". Acrescenta, ainda, dizendo que é muito comum, no mundo masculino, justificar a não-inserção no trabalho doméstico com frases como esta: "não trabalho, porque lugar de homem não é na cozinha”.

Também com base nessa perspectiva, "de que lugar de homem não é na cozinha", é que todos os contratos de emprego doméstico são realizados entre as mulheres. Os homens não costumam interferir nesse campo, a não ser quando eles moram sozinhos, como afirma Preuss (1996). Assim sendo, esse autor declara que o trabalho doméstico contratado continua reproduzindo a divisão sexual do trabalho, já que efetiva apenas um pequeno envolvimento do marido na manutenção da casa. Se a tarefa doméstica é uma coisa de mulher, nada mais coerente com esse pensamento que a esposa, a dona da casa, lance mão da responsabilidade de tudo que concerne à empregada, inclusive, muitas vezes pagando de seu próprio salário as despesas com trabalhadores domésticos, uma vez que isso é uma responsabilidade dela.

Outra fala que destaca a presença do homem neste serviço, reforçando a idéia disseminada entre as entrevistadas de que o trabalho doméstico é algo feminino é a de uma das jovens, que afirma:

\section{Qualquer um pode mesmo (executar o serviço doméstico), porque hoje em dia tem homem que faz coisa melhor que a mulher, na cozinha. Assim, na maioria dos restaurantes, tem que ter um viado no meio pra tá fazendo as coisas.}

O que chama a atenção nesse discurso é o fato de o homem poder executar as tarefas domésticas, porém, com isso, perder sua masculinidade. Tendo em vista os papéis que homens e mulheres desempenham dentro de uma casa, na contratação de uma empregada, reforça-se que o trabalho doméstico ainda tem só um sexo, o feminino. Sendo assim, esta forma de trabalho, por suas condições mesmas, é uma importante reprodutora das desiguais relações de gênero. Esta Psico-USF, v. 10, n. 1, p. 93-102, jan./jun. 2005 reprodução ocorre tanto por parte dos membros das famílias quanto pelas mulheres implicadas nesta realidade, já que, no fundo, acabam perpetuando o lugar feminino como o de mantenedor e reprodutor do espaço privado e o homem fora do espaço doméstico, como já ressaltado anteriormente.

Anderfuhren (1999) aponta que as trabalhadoras domésticas pouco mencionam os patrões, muitas vezes, nem sabendo em que trabalham. Eles são mencionados quando há algum caso de assédio, variando desde observações grosseiras até tentativas de estupro. Muitas jovens entrevistadas mantêm uma relação de distância com os patrões homens, pois têm vergonha de pedir ou perguntar alguma coisa a eles. Eles, tampouco, se relacionam com as empregadas ou se dirigem a elas. A relação entre o patrão e a empregada doméstica parece ser muito delicada, podendo ir desde a frieza e a nãocomunicação até ao abuso, tendo em vista que o campo da sexualidade está presente entre os dois.

Nenhuma das jovens entrevistadas afirmou passar por uma situação de abuso sexual, mas, às vezes, afirmam que pode haver um abuso de confiança. Evidentemente, concorda-se com Anderfuhren (1999) quando atesta que o mais comum entre as jovens que passam por uma situação de abuso é ficarem em silêncio. Contudo, o momento de uma entrevista individual é insuficiente para detectar esse tipo de relação entre patrão e trabalhadora.

Esse tipo de situação é um dos maiores riscos que corre uma empregada doméstica, principalmente aquelas que residem com os patrões, uma vez que o homem tem livre acesso ao local de moradia e à adolescente. Assim sendo, Preuss (1996) atesta que as mulheres controlam a sexualidade das empregadas, para que elas não despertem o interesse dos filhos e do marido.

\section{Referências}

Aguiar, N. (1997). Perspectivas feministas e o conceito de patriarcado na sociologia clássica e no pensamento sócio político brasileiro. Em N. Aguiar (Org.). Gênero e ciências humanas. Coleção gênero, 5. Rio de Janeiro: Record; Rosa dos Ventos.

Anderfuhren, M. (1999). A comida do rico às vezes não dá saúde! Condições de vida e saúde das empregadas domésticas do Recife. Texto apresentado para o II Congresso Internacional, Mulher, Trabalho e Saúde. Rio de Janeiro.

Andrade, M. A. G. (2000). Para estudiar la relación entre el trabajo doméstico y la salud de las mujeres (texto não publicado).

Bento, M. A. S. (1995). A mulher negra no mercado de trabalho. Estudos Feministas, 3(2), 479-487. 
Black, M. (1997). El trabajo doméstico infanto/juvenil: manual de investigación y acción. Anti-Slavery International.

Bourdieu, P. (1996). Novas reflexões sobre a dominação masculina. Em M. J. M. Lopes, D. E. Meyer \& V. R. Waldow. Gênero e saúde (pp. 28-40). Porto Alegre: Artes Médicas.

Bruschini, C. (1990). Mulher, casa e familia: cotidiano nas camadas médias paulistanas. São Paulo: Fundação Carlos Chagas; Vértice.

Cervini, R. \& Burger, F. (1996). O menino trabalhador no Brasil urbano dos anos 80. Em R. Cervini \& F. Burger. O trabalho e a rua: crianças e adolescentes no Brasil urbano dos anos 80. 2a ed. São Paulo: Cortez.

Combes, D. \& Haicault, M. (1986). Produção e reprodução. Relações sociais de sexos e de classes. Em A. Kartchevsky-Buport et al. O sexo do trabalho (pp. 2344). Rio de Janeiro: Paz e Terra.

Dantas, M. C. (2000). A adolescente empregada doméstica. Texto mimeografado produzido pela auditora fiscal do trabalho da Delegacia Regional do Trabalho do Rio Grande do Norte, em 14 set. 2000.

Donzelot, J. (1986). A polícia das famílias. 2a ed. Rio de Janeiro: Graal.

ECA - Estatuto da Criança e do Adolescente (1994). São Paulo: Saraiva.

Freire, J. C. (1970). Ordem médica e norma familiar. Porto Alegre: Artes Médicas.

Gouveia, T. \& Camurça, S. (1997). O que é gênero. Cadernos SOS Corpo Gênero e Cidadania, Recife: SOS Corpo.

Hirata, H. \& Kergoat, D. (1994). A classe operária tem dois sexos. Estudos Feministas, 2(1), 93-100.

IBGE - Instituto Brasileiro de Geografia e Estatística. (2002). Pesquisa Nacional por Amostragem de Domicílio PNAD/2001. Rio de Janeiro: IBGE

Lobo, E. S. (1992). O trabalho como linguagem: o gênero do trabalho. Em A. de O. Costa \& C. Bruschini
(Org.). Uma questão de gênero (pp. 252-265). São Paulo: Fundação Carlos Chargas.

Madeira, F. R. (1997). A trajetória das meninas dos setores populares: escola, trabalho ou reclusão. Em F. R. Madeira (Org.). Quem mandou nascer mulher? Estudos sobre crianças e adolescentes pobres no Brasil (pp. 45-133). Rio de Janeiro: Record; Rosa dos Tempos.

Melo, H. P. (1998). O serviço doméstico remunerado no Brasil: de criadas a trabalhadoras. Texto para discussão 565. Rio de Janeiro: IPEA.

Meyer, D. E. (1996). Do poder ao gênero: uma articulação teórico-analítica. Em M. J. M. Lopes, D. E. Meyer \& V. R. Waldow. Gênero e saúde (pp. 41-62). Artes Médicas: Porto Alegre.

Mota, A. B. (1989). Emprego doméstico: revendo o novo. Caderno $\mathrm{CRH}, 16,31-50$.

Oliveira, E. M. (1999). A mulher, a sexualidade e o trabalho. São Paulo: Hucitec.

Preuss, M. R. G. (1996). Patroas e empregadas: relações de proximidade e oposição. Coletâneas da ANPEPP, 53-65.

Sabóia, A. L. (2000). As meninas empregadas domésticas: uma caracterização socioeconômica (versão preliminar). IBGE.

Saffioti, H. (1994). Pósfácio: conceituando gênero. Em H. I. B. Saffioti \& M. Muñoz-Vargas (Org.). Mulher brasileira é assim (pp. 71-183). Rio de Janeiro: Rosa dos Ventos.

Spink, M. J. P. (Org.) (2000). Práticas discursivas e produção de sentidos no cotidiano: aproximaçoes teóricas e metodológicas. 2a ed. São Paulo: Cortez.

UNICEF (Org.) (1997). Situação mundial da infância 1997. Brasília: UNICEF.

Recebido em julho de 2004 Reformulado em outubro de 2004 Aprovado em junho de 2005

Sobre as autoras:

Munich Santana é psicóloga, mestre em Psicologia pelo Programa de Pós-Graduação em Psicologia da Universidade Federal do Rio Grande do Norte.

Magda Dimenstein é doutora em Saúde Mental, professora adjunta do Departamento de Psicologia e coordenadora do Programa de Pós-Graduação em Psicologia pelo Instituto de Psiquiatria da Universidade Federal do Rio Grande do Norte. 